\title{
Tunnetusti ja tiedetysti queerit
}

\section{Joonas Säntti}

Seksuaali- ja sukupuolivähemmistöjen näkyvyys suomalaisessa kirjallisuudessa on tuskin koskaan ollut yhtä huomiota herättävää kuin pitkäksi venähtäneen pandemiakauden aikana. Kirjakatsaukseni kohteena ovat 2020 ja alkuvuodesta 2021 julkaistut, autofiktioksi tai (ainakin osittain) omaelämäkerralliseksi kertomakirjallisuudeksi luonnehditut tekstit, joissa homoseksuaalisuus tai seksuaalivähemmistöjen asema on erityisen keskeinen teema. Rajaus jättää ulkopuolelleen esimerkiksi esseeteokset ja runouden, historialliset romaanit, sarjakuvat sekä tietysti ne fiktiiviset proosateokset, joissa henkilöiden seksuaalinen orientaatio jää maininnan tasolle.

Näinkin tiukka rajaus tarjosi kahdeksan teosta: Antti Holman Kaikki elämästäni (Otava, 2020), Tuuve Aron Kalasatama (WSOY, 2020), Tiina Tuppuraisen Kuvittelen sinut vierelleni (Karisto, 2020), Essi Kummun Loiste (Tammi, 2020), Laura Lehtolan Minä valitsin sinut (Otava, 2020), Gekko Paavilaisen Yksisarvinen (Ntamo, 2020), Janne Saarakkalan Sen pituinen se (Like, 2020) ja Niko Hallikaisen Kanjoni (Otava, 2021).Valittujen tekstien omaelämäkerrallisuus tosin vaihtelee merkittävästi, ja joissain tapauksissa sen voi väittää perustuvan lähinnä parateksteihin tai mediajulkisuuteen, esimerkiksi tekijähaastetteluihin.

Valinta ei pyri kattamaan queerin seksuaalisuuden saati genderqueerin koko kirjoa kyseisellä aikavälillä. Esimerkiksi Taneli Viljasen Varjoja, usvaa (2020) ja Suvi Auvisen Kaltainen valmiste (2021) jäävät käsittelyn ulkopuolelle. Kirjoitukseni ei ole arvostelu, jossa vertailtaisiin kirjojen esteettistä kiinnostavuutta tai onnistuneisuutta. Poimin valikoiden teksteistä toistuvia, usein jo tunnettuihin aikalaiskeskusteluihin liittyviä aiheita ja teemoja, mutta myös joitain lajiin ja tyyliin liittyviä ratkaisuja. Minua kiinnostavat erityisesti halun ja identiteetin sekä poliittisen ja tekstuaalisen queerin leikkauspisteet.

\section{Identiteetit edellä}

Aloitan helpolla yleistyksellä: seksuaalisuutta käsitellään teoksissa yleisimmin identiteetin kysymyksenä. Usein se näyttäytyy päähenkilöiden sisäisenä om(in)aisuutena, joka määrittää pitkälle myös muun elämän suuntaa, kasvamista joksikin tietyksi, kuten homoksi, lesboksi tai biseksuaaliksi, tiettyjen yhteisöjen sisällä. Kuten Essi Kummun teoksessa todetaan, "homoseksuaalinen teko" voi tarkoittaa mitä tahansa jaettua kokemusta tvsarjan katsomisesta samassa joukkueessa pelaamiseen $(L, 51$.

Seksuaalinen orientaatio näyttäytyy teoksissa sisäsyntyisenä ja yleensä varhain ruumiillisesti tunnettuna. Kirjojen kertojat tai näkökulmahenkilöt pelkäävät jo nuorina sopimattomuutensa paljastumista. Kalasataman kertoja muistelee pientä partiolais-minäänsä vaeltamassa synkässä metsämaassa,
Pervopeili Keskustelut 
"peruuttamattomasti erilaisena, katoavaisena ja yksin" (KS, 24). Holman tragikoomisessa perhekuvauksessa paljastumisen ja häpeän airuena toimii joulupukki, joka tietää nuorten poikien pyllyleikeistä. Joulupukin katse seuraa vielä aikuista homomiestäkin, kun häpeä yllättää.

Holman kirjassa kuljetaan Sonkajärveltä Helsinkiin ja lopulta ulkomaiden metropoliksiin. Saarakkalan henkilögallerialtaan laajemman romaanin 1990-luvun vaihteen koululaiset muuttavat Kemistä Helsinkiin ja sen kautta maailmanvalloitukseen. Paavilaisen Yksisarvisessa nuori Reko muuttaa 1992 Kainuusta Tampereelle, jossa voi "löytää sen mikä tai mitä mä olen" (YS, 13). Tampere näyttäytyy nuorelle miehelle sallivalta ja kokeiluihin kutsuvalta paikalta, joka "suorastaan vilisi yksisarvisia" (YS, 132). Tällainen maaseudulta kaupunkiin -asetelma on perinteinen kulttuurin kaapistatulokertomuksissa ja toisaalta yleisemmin kehitysromaanin juonikonventioissa. Siihen liittyy luontevasti alayhteisön merkitys seksuaali-identiteetin kehityksessä. Kaupungeissa kohdataan elävien vähemmistökulttuurien todellisuus, homo- ja lesbobaarien säännöt ja koodit, piirien sisäiset valtaasetelmat ja mahdollisuudet.

Nykykirjallisuudessa queerin yksilön kehityskertomus on usein juonellisesti ja temaattisesti sidottu alakulttuurien representaatioon, toisin sanoen minän löytäminen on myös oman yhteisön löytämistä. (Ks. esim. Miller 2018.) Aro, Tuppurainen, Saarakkala ja Lehtola kuvaavatkin Helsingin 1990-luvun homo- ja lesbobaarien elämänmenoa tarkkuudella, johon oikeiden baarien, mediakohujen ja pop-referenssien nimeäminen tuo dokumentaarista toden tuntua.

Kummun Loiste sijoittuu Pohjois-Suomen paikkakunnalle, jossa on tiettävästi kolme naispariskuntaa, joten tietoisuus katseista tuottaa suhteelle erilaiset edustavuuden paineet. Naisten parisuhteen on onnistuttava, sen on oltava esikuvallisen harmoninen: "Olemme saaneet toisemme ja nyt meidän kuuluu olla onnellisia. Muille tämän tulee näyttää siltä että olemme ratkaisseet persoonaamme ja identiteettiämme koskevat kysymykset ja sijaitsemme nyt rauhan satamassa, eikä mitään keskeneräisiä kohtalonkysymyksiä ole selvittämättä." (L, 50, ks. myös Lahti 2021.)

Ulostuleminen ei siis tarkoita rajahetkeä, jonka jälkeen vapauduttaisiin toisten katseiden ajattelusta, ehkä jopa päinvastoin. Kummun teoksessa ensimmäistä kertaa julkisesti lesbosuhteessa elävät esiintyvät" julkisesti kuin ystävykset, jotka toisinaan hoitavat yhdessä lapsia" $(L, 90)$. Samalla kertoja tulee vahvistaneeksi toisten katseiden tarpeen, koska vasta näkyvyys tekee suhteen todellisemmaksi, yhdenlaisena vastavoimana vakiintuneelle heteroseksuaaliselle perhekuvastolle. Sitä edustaa kertojalle puolison entinen vihkikuva tämän vanhempien kotiseinällä.

Orientaatio eli suuntautuminen, samoin kuin queer, samoin kuin pervous, ovat tietysti jo itsessään tilallisia käsitteitä. Kuten Sara Ahmed pohtii (2006, 68-79), heteroudesta erkanevat orientaatiot ovat eksymistä suoralta polulta, antautumista arvaamattomalle, toisinaan tietoista poiskääntymistä. Romaaneissa tällaista vertauskuvallisuutta hyödynnetään tuon tuosta. Tuppuraisen kirjan päähenkilö Annille "cis-miehet ovat tylsä ja tasainen asvalttitie keskellä maisemaa, naiset piilossa oleva metsäpolku, jonka määränpäästä ei ole varmuutta" (KSV, 220). Aron Kalasatamakin alkaa sopivasti Dante-sitaatilla, jossa kuljetaan "tieltä oikealta" eksyneenä (KS, 5). Heteroseksuaalisuus puolestaan kirjataan vahingoniloisesti vankilaksi, elinikäiseksi rangaistukseksi.

Seksuaalisuuden ohella toinen poikkeusasetelma on lähes yhtä ilmeinen ja toisinaan myös temaattisesti keskeisempi: taiteilijuus. Omaelämäkerrallisuuden huomioiden siinä ei tietysti ole mitään yllättävää. Se kuitenkin tuo suurimpaan osaan kirjoista yhtäältä kiinnostavia metatasoja, toisaalta vähemmistöjen representaatioiden tarkastelua. Ovat päähenkilöt sitten erisnimin ja taustatarinoin fiktiivistettyjä hahmoja tai helpommin tekijän ääneksi tulkittavia kertojahahmoja, juuri taiteilijan vapaus ja vastuu, tie- 
toisuus omasta roolista ja siihen liittyvistä julkisista odotuksista nousevat jatkuvasti esille.

Kalasatamassa nuorta kirjailijaa ahdistaa pelko "yhden asian kirjailijaksi" (185) joutumisesta lesbokirjaililijana, toisaalta naiskirjallisuuden odotushorisontti, jonka vuoksi teoksia luetaan naisen henkilökohtaisina tarinoina laajemman yhteiskuntakritiikin asemasta. Nämä huolet muistuttivat Jeanette Wintersonin, Ali Smithin ja Sarah Watersin tapaisten, kansainvälisesti tunnettujen tekijöiden kommenteista. Mutta Aron kertojaa ärsyttää yhtä lailla erojen lakaiseminen maton alle kattavan ja pohjimmiltaan alentuvaisen suvaitsevaisuuden nimissä. Tekijän voi joko lokeroida tai universalisoida merkityksettömäksi.

Holman Kaikki elämästä(ni) ottaa huumorinsa maalitauluksi omaelämäkerrallisen kirjallisuuden kliseet ja kirjoittajalta odotetut turvalliset vähemmistöaiheet kuten homofobian ja erilaisuuden pelon. Holman kirjan "Antti Holma" ei halua tulla siksi kirjailijaksi, joka kirjoittaa kärsivän homolapsen kohtalosta maaseudulla ja paosta suurkaupunkiin (KE, 52). Osa ironiaa lie siinä, että jotain tällaista asetelmaa kirjassa kuitenkin on.

Saarakkalan luomista keskushahmoista vahvimmin itseanalyyttinen, Valtteri, ajattelee identiteettikertomuksia ohjaavia "metafantasioita", niitä homomiehen roolimalleja, joiden täyttämisestä saa omanlaistaan nautintoa. Homosubjektin kannalta yksi tällainen liittyy loputtomaan seksiin, ikuiseen ihanaan siveettömyyteen. Kun kemiläinen Tomi tipauttaa nimensä viimeisen kirjaimen, hänestä kukkii esiin Tom, kaikkien haluama ja ainavalmis maailmankiertäjä, yhdenlainen populäärimyyttien tiivistymä: "Marlboro-mies, Genet'n selkään puukottava seilori, kulkurihuora" (SPS, 187).

Keskustelevan aateromaanin suuntaan kumartava Sen pituinen se käsittelee empaattisesti, traagisen ironian sävyin 1990-luvun nuorten hapertuvaa uskoa seksuaaliseen vapautumiseen ja vallankumoukseen. Nuoret kapinalliset uskovat, että yksilön rohkea elämäntapavalinta toimisi energialähteenä, joka voisi murtaa porvarillisuuden, heterouden ja kapitalismin pyhän kolmiyhteyden. "Heidän omat halunsa häikäisivät heidät" markkinaliberalismin kyvylle sulauttaa itseensä kaikki seksuaalisen kapinan muodot: "nauti, niin olet" (SPS, 289).

Identiteetti-ja kehityskertomuksista poikkeaa voimakkaimmin Hallikaisen Kanjoni, joka pyrkii muutenkin eroon proosakerronnan konventioista. Toisteiset ja silti yllättävät, korostetun kaunokirjalliset kuvailut masturbaatiosta ja seksiakteista tekevät selkeimmin pesäeroa narratiivisen elämäkirjoittamisen odotuksiin. Hallikaisen proosa ei perustu tarinalliselle kausaliteetille, vaan jatkuvuus liittyy enemmän havaintoihin ja juolahduksiin, kielikuvien hyökyyn: "Niklas rasvaa kulliaan peräaukkoni suulla kuin surffilautaa, mietin, tekeekö se minusta aallon" $(K, 27)$. Tämä ei tarkoita hahmojen identiteettiin liittyvien erojen merkityksettömyyttä: erään tulkinnan mukaan kertojan työväenluokkaisuus on kehollisuuden kannalta erityisen merkittävää (Luhtaniemi 2021).

\section{Kuka saa kuulua}

"Te ette oikeasti tiedä, mitä on kasvaa ja elää seksuaalivähemmistössä", Aron kertoja-minä puhuttelee "purnaavia" biseksuaaleja. "Voitte väittää tietävänne, mutta ette tiedä". (KS, 81.) Väite on aika voimakkaita kategorisia mielipiteitä tarjoavan Kalasataman silmiin pistävimmistä päästä.

2020-luvun vaihteen proosassa sateenkaarivähemmistöjen sisäinen historia näyttäytyy toisinaan kinastelun, nokittelun ja suoranaisen vittuilun areenana. Kalasataman sivuilla kuvatut bi-naiset ovat etuoikeutettuja valittajia, joiden tapa kritisoida lesbopiirien kapeutta on "itsesuojelua" omien etuoikeuksien kohtaamiselta. Ylpeys omasta seksuaalisuudesta 
elämäntapana tuntuu vaativan toisten vähemmistöjen vähemmistöaseman kyseenalaistamista.

Kertojanääni tarjoaa kolme ehdotusta selitykseksi biseksuaaliliittojen heterokeskeisyyteen: 1) helppous ja turvallisuus, 2) kiinnostuksen etsintä, 3) oman oikean seksuaalisuuden kieltäminen (KS, 82). Yksi asia tuntuu yhdistävän kolmikkoa: kyse ei ole autenttisesta halusta vaan puhtaasta valinnasta. Tällaisen ajattelumallin mukaan miehen kanssa seurusteleva biseksuaali ei oikeasti olisi jotain muuta kuin hetero. Asenne on tietysti äärimmäisen tuttu bifobian historiaan perehtyneille.

Seksuaalipolitiikan erot taustoitetaan sukupolvikysymyksenä: oman aikamme queer-nuoriso on pinnallista, muodikasta, itsekästä ja historiatajutonta, ja valmis vaihtamaan identiteettiään jopa "päivätahtiin"; sen sijaan Aron kertojaminän tapaisella "vanhan liiton lesbolla" on omasta kapinallisuudestaan käsin jonkinlainen suora yhteys Stonewallin kapinallisiin. (KS, 136-139.) Kiinnostavasti sukupuoli todetaan pohjimmiltaan kulttuuriseksi konstruktioksi ja kasvatuksen tulokseksi, mutta homoseksuaalisuus nähdään kiistattomana minuuden osana. Se voi olla poliittista ja "myös esteettinen näkemys" (KS, 79). Vaikuttaisi, että oikeus vähemmistöidentiteettiin tulisi ansaita kokemalla tietty määrä negatiivisia tunteita, joissa suuntautuneisuus koetaan pakenemattomaksi ja peruuttamattomaksi. Muuten on liian helppoa, ja Aron kertojaa "helppo ei kiinnosta". Trans-ihmiset ovat Kalasatamassa esillä aiemman yhteisönsä hylänneinä transmiehinä, joista on kasvanut sovinisteja ja toisaalla transvestiitteina, joiden peilailu on naurun kohteena.

Vähemmistöjen väliset ja sisäiset ennakkoluulot ovat esillä myös Tuppuraisen ja Lehtolan vähemmän räväkästi väittävissä romaaneissa. "Miksi naisellinen lesbo olisi vähemmän lesbo kuin maskuliininen?" Tuppuraisen kertoja ihmettelee, ja jatkaa pohtimaan 1990-luvun lesbokulttuurin suhteissa toteutuvaa vastaparien logiikkaa $(K S V, 22)$. Jokseenkin täydellisenä vastakohtana Aron tyylille Tuppuraisen eri nimellä merkitty minä-kertoja (Anni) kokee jatkuvaa syyllisyyttä myös oman ajattelunsa asenteellisuudesta.

Lehtolalla muutoksen käsittely tapahtuu fiktiohenkilöiden kautta näkökulmitettuna muisteluna: "Kymmenen vuotta sitten kaikilla lesboilla oli lyhyet hiukset ja uhmakas ilme, eikä biseksuaaleja ollut kuin netissä ja epätoivoisissa heterosuhteissa. Polyamorisia oli korkeintaan amerikkalaisissa dokumenteissa." (MVS, 141.) Tuppuraisen kirjassa nuorempaan ruotsalaiseen ihastuva Anni kohtaa Z-sukupolven halun laajentaa seksuaalisuuden pudotusvalikoiden joukkoa ja toisaalta puhua naisten ja miesten sijaan ihmisistä.

Autofiktio sallii oikeuden luovaan liioitteluun ilman ironisen pilkkeen jatkuvan esille kirjoittamisen tarvetta. Tuuve Aron tyylistä haistaa tietoisen provokaation. Toisaalta huomasin kysyväni mikä itse esityksessä, itse tekstin äänessä, oikeastaan erottaa tietäväisen, itsevarmasti toisten kokemusten päälle kirjoittavan äänen keski-ikäisten urosten mansplainauksesta? Ja jos takaisin päin kategorisoidaan: Onko keski-ikäisen valkoisen lesbonaisen sapenpurku automaattisesti poliittisesti radikaalia? Asuisiko poteroissa pelko siitä, että oma vähemmistöasema ei enää olekaan niin ilmeistä ja siitä käsin kirjoittaminen lähtökohtaisesti niin rohkeaa kuin oman identiteettikertomuksen kannalta haluaisi ajatella?

Tuppuraisen ja Lehtolan teoksissa sallivuuden ja samanmielisyyden illuusiota puretaan eri keinoin. Sateenkaaripolitiikan keskiluokkaistuminen näyttäytyy valikoivana värisokeutena, jonka avulla luodaan valheellista mielikuvaa erilaisten yhteisöstä. Kuvittelen sinut vierelleni esittelee sivulla 225 sivuhenkilön, jonka selkeänä funktiona on välittää näkökulma aktivismin sokeista pisteistä, ennen kuin poistuu teoksesta kaksi sivua myöhemmin: "Moni asia on muuttunut, Mikael sanoo, mutta transsukupuoliset, polyamoriset, sadomasokistit, queerit, aseksuaalit, nahkahomot ja ei-valkoiset eivät mahdu vieläkään kunnolla sateenkaaripolitiikan sisälle [...]” 
Kirja nostaa samalla tavalla esille sukupuoleltaan ei-binääristen kokeman väkivallan (218), ja kertoja ottaa suoraan etäisyyttä myös transfobisten terffien aatemaailmaan. Transsukupuolisuus kummittelee monessa tekstissä sivuaiheena, ja siitä kerrotaan oikeastaan toistuvasti sama: trans-ihmisten näkymättömyys ja marginaalisuus, jota kirjat eivät tietenkään voi olla samalla toistamatta, vaikka intentio olisi nimenomaan tasa-arvoistamiseen pyrkivä. Tekstimäärän jakautuminen pikemmin todistaa siitä, että tässäkin lajissa demokraattisuus on illuusio. Trans-hahmot tapaavat olla juonellinen poikkeama, joka otetaan mukaan osoittamaan, että ongelma kyllä tiedostetaan.

Yksi kategoria tuntuisi säilyttävän kiistattoman voimansa kirjasta toiseen: heterous. Mutta mitä sillä tarkoitetaan? Nykyfiktiota seuraava huomaa nopeasti, että sanasta on tulossa likipitäen synonyymi normatiiviselle heteroseksuaalisuudelle. Sen ytimessä on normaalius, kulttuurinen keskimäääisyys. Holman fiktiominän on helppo kuvitella "normaali, tyhmä, tylsä hetero" toteuttamassa kaikkia suomalaisen maskuliinisuuden absurdeja ja silti itsestään selviä rituaaleja. Sami Hedberg ja jääkiekko ovat samassa linjassa kuin "heteroseksuaalinen kanssakäyminen" (KE, 45, 114). Kyse on siis "heterokulttuurista" (76), ja retorisesti se asetetaan ainakin kahdella tavalla vastakohdaksi sille mitä kirjojen hahmot edustavat. Ensin kertojat/ henkilöt vakuuttavat kyvyttömyyttään ymmärtää sitä (nuo heterot outoine tapoineen) mutta toisaalta he toteavat ymmärtävänsä sitä turhankin hyvin, nähden suoraan tylsyyden ytimeen (normimassat vastakohtana itseidentiteetille). Heterous asuttaa esimerkiksi Dynamon tanssilattiaa, sen geneeristä tyylikkyyttä ja sallivaa "vaihtoehtoisuutta", joka muistuttaa Tuppuraisen romaanin Annia liiaksi siitä mitä hän on päättänyt jättää taakseen $(K S V, 100)$.

Missä sitten sijaitsevat ne lukuisat cis-heteroiksi määrittyvät ihmiset, jotka satunnaisesti ristiinpukeutuvat, harrastavat homoseksiä kokeilumielessä, nauttivat pyllyn nuolemisesta ja eri objektien anaaliin insertoimisesta, sidonnasta ja alistamisesta, polyamoriasta ja age play -skenaarioista? Missä kohtaa nuo heterot lakkaavat olemasta normatiivisesti "heteroita"? Tällaiset kysymykset eivät kiinnosta minua siksi, että kaipaisin jonkinlaista reilua, jopa heterot huomioivaa tasapainoisuutta. Kiinnostavampaa on mahdollisuus queerin laajentamiseen. Silloin kun puhutaan halusta ja akteista, puhutaan väkisin jostain muustakin kuin identiteeteistä. Tällöin seksuaalisuus voi merkitä myös minän kadottamista ruumiilliseen kokemukseen, tai Barbara Johnsonin $(2014,152)$ sanoin: "[T] he body's own denial of the category of identity? What if sexuality were not a type of identity but a type of loss of identity?"

\section{Kirjojen queer kirjo}

Laura Lehtolan tyyliltään perinteisen romaanin omaelämäkerrallisuus on korostunut vastaanotossa, koska päähenkilön elämäntilanne muistuttaa etäisesti kirjailijan omaa. Kirjassa lesbosuhteessa elävän naisen perhe-elämä ja identiteetti kriisiytyvät, kun hän huomaa ihastuvansa mieheen. Holma, Aro, Kummu ja Hallikainen leikittelevät tosielämän ja fiktion sekoittamisella, tematisoiden myös lajiodotuksia, mutta Lehtola on rakentanut puhtaammin omissa kansissaan pysyttelevän romaanin, jossa ajankohtaisia aiheita käsitellään vaihtelevan näkökulmakerronnan ja dialogin kautta. Siinä missä Kalasatama nostaa suoraan pöydälle käsitteen vähemmistöstressi ja tarjoaa sen yleismääritelmän (76), Minä valitsin sinut esittää Saaran kertomassa Antille: "alusta saakka tässä suhteessa on enemmän tai vähemmän aina pähkäilty mitä joku ajattelee tai ajattelisi siitä tahi tästä. [... ] Ja vaikka nykyään mielipideilmasto on muuttunut ja 'ajat erilaisia', se kaikki on liimaantunut itseen niin että ei sitä vaan saa irti." (157.)

Vaikka seksuaalisuuden kuvauksissa ei enää sievistellä, seksiaktien kuvaaminen on yleensä sittenkin viitteellistä. Tässä kirjavalikoimassa miehen nimiset kirjoittivat tarkempia ja pidempiä kuvauksia fyysisistä teoista 
ja niiden tunnusta. Paavolaisen kirjan kertoja kuvaa löytöretkeilyään mutkattoman jutustelevaan sävyyn, tosin juuri fyysisten ilojen kohdalla vertauskuvat voivat olla aika villejä. Rakastajan terska on "kova kuin järjestyksenvalvojan pampunpää tai kivettynyt kriikuna" (YS, 161).

Saarakkalan romaani sai tuoreeltaan runsaasti huomiota homoseksin häpeilemättömästä kirjoittamisesta. Seksiaktien ja mieltymysten kuvaukset eivät ole erityisen eksakteja ja herkuttelevia, eivät enempää shokeeraavan rivoja kuin kutkuttelevan kaksimielisiä, pikemmin hyvin asiallisia havaintoja esimerkiksi tottumuksista. "Hän ei ole mikään syväkurkku, enemmän terskan päätä lipovaa tyyppiä." (SPS, 133.) Seksiakteihin liittyvien aistimusten kuvailu tavallaan arkistaa niitä, vertaukset eivät romantisoi mutta eivät myöskään nautiskele alatyylisyydestään. Peräaukkoon työnnetty penis on "ei miellyttävä mutta ei sietämätönkään tunne, kuin pökäle liikkuisi siellä edestakaisin", ja peräaukon maku on kuin "hiellä suolattu umami" (SPS, 175). Tällaiset kiinnittävät huomiota suorasanaisuudessaan, mutta mitään erityisen härskiä yksityiskohdissa ei ole.

Hallikaisen tietoisen kohtuuttomat kuvaukset netin runkkaushuoneiden kuvavirrasta ovat eri tavalla häiritseviä. Kun aktin toiset osapuolet eivät ole taustoitettuja henkilöhahmoja vaan sarja kuvia, samanaikaisesti äärimmäisen tosia ja sittenkin virtuaalisia, yhden klikkauksen päässä ja yhdellä klikkauksella katoavia, kontakti jää myös affektiivisesti hämäriksi. Halussa sekoittuvat tirkistelevä väkivalta, samastuminen ja välillä aukeava mahdollisuus erillisen minuuden kadottamiseen: "Voin jo tuntea kasvojen poltteen persereikääni vasten, nuolemassa minua auki. Hän viipyy elämässäni vain muutaman sekunnin niin kuin kuka tahansa ihminen. Oloni on helpottunut, kun hän katoaa, sitten helpotuksen tunne harmittaa." $(K, 37$.

Toiset kirjat osoittavat autofiktion venyvyyden ja vapaan liikkumisen fiktion ja tietokirjallisuuden välimaastossa. Esimerkiksi Aro ja Tuppurainen kirjoittavat varsin suoraa aikalaisilmiöiden ruodintaa sukupuoli- ja luokka- asetelmista, häirinnästä, rasismista ja etuoikeuksista. Kirjoitus lähestyy välillä tyyliltään journalistista miniesseetä. Amerikkalaisen kulttuurin vaikutus on silmiin pistävän voimakas. Tuppuraisen kirjassa San Francisco toimii suomalaisen lesbon pyhiinvaelluspaikkana ja L-koodi on se mistä rooleja nuorena opiskellaan.

Ajallisesti hyppivä juonirakenne ja parin-kolmen hahmon välillä vaihteleva näkökulmakerronta ovat pitkään kuuluneet 2000-luvun valtavirtaproosan vakioratkaisuihin. Kummun katkonaisempi, virkerakenteissaan modernismin suuntaan kumartava Loiste eroaa kuitenkin tässä merkittävästi Lehtolan tai Saarakkalan valtavirtaisemmasta tarinankerronnasta. Kummun proosa tuntuu varovan sulkeumia ja kehitystarinoita parisuhteen kuvauksessa. Tunne pysyvän onnen löytämisestä ja eroamisen tosiasia vuorottelevat kirjan loppupuolella niin tiiviisti, että ne vaikuttavat miltei samanaikaisilta tapahtumilta. Lukijan on pakko pysähtyä miettimään keskenään irrallisilta tuntuvien jaksojen logiikkaa: miksi tästä kerrotaan juuri nyt? Toisin kuin Lehtolalla ja Tuppuraisella, tekstin jännite ei rakennu suoraan sen varaan, mitä naisten parisuhteelle tapahtuu. Peilistä heijastuva, hääpukuun sonnustautuneen rakastetun katseen loisto kuitenkin säilyy pre(e)senssinä, jää ikään kuin kummittelemaan kirjan viimeisiltä sivuilta.

Kummun vaihteleva ensimmäisen ja kolmannen persoonan kerronta ja epälineearisesti etenevä aika, kuten myös Hallikaisen liioittelevat deskriptiot ja yllättävät tila-asetelmat, muistuttavat lukijaa kirjoittamiseen liittyvistä valinnoista ja sanataiteen lähtötilanteista, tekstistä tekstinä. Samalla ne havainnollistavat, miten kirjoittaminen voi toimia keinona lähestyä seksuaalisuutta jännittävästi ja vinosti, sen tunteellisesti epämääräisiä sävyjä kunnioittaen. Ehkä voisi puhua queeristä taiteellisena tyylin tai kerronnan ratkaisuna, sen sijaan että sitä katsottaisiin jo tiedetysti queerin representaationa. Tällöin queer asuu yhtä paljon tai enemmänkin kirjoituksessa kuin siinä mistä kirjoitetaan.

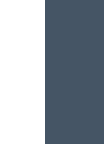

.
} 
Toisenlainen queerin ja identiteettikategorioiden kohtalonyhteyden purkaminen voisi liittyä vähän perinteisemmin kerrottuun tasoon: hahmojen välisiin tarinallisiin jännitteisiin. Saarakkalan romaanissa Erika on kiinnostunut lesboseksistä, mutta vain tiukasti homoseksuaalin parhaan ystävänsä Tomin kanssa. Tomin feminiininen antautuvuus kiihottaa Erikaa, joka haluaisi olla se, joka "panee”. Ystävien välinen jännite ei kuitenkaan ole yksipuolista, vaan myös Tomi kiihottuu erityisesti tilanteesta, jossa Erika rankaisee häntä vitsalla pakaroille. "Ei siihen aina mulukkua tarvita", Tomi toteaa jälkikäteen, koska piiskaaminen on "vähä niinku panemista" (SPS, 126.) Jos akteja lähestyy subjektiivisen kokemuksen tasolta, kategorioita ylläpitävä logiikka ainakin vähän liikahtelee sijoiltaan, romaanin juonesta huolimatta? Ja jos queeria ajattelee halun arvaamattomuutena tai kategorioiden hämmentämisenä, Saarakkalan romaanissa se saattaakin ilmetä esimerkiksi "heteron” Erikan ja Tomin välisessä suhteessa.

Tekijäkeskeisessä kirjallisessa kulttuurissamme suurin huomio liittyy representaatioihin, toisaalta autenttisuuteen. Oliko kuvaus uskottava, onko se kyllin kokemusasiantunnettu? Kirjoja lähestytään helposti dokumentteina ja niiden osumatarkkuus liitetään kattavuuteen: oliko tämä nyt pätevä kuvaus siitä, miltä tuntui kasvaa homona 1990-luvun vaihteessa? Muistettiinko myös nämä ja nämä ilmiöt mainita? Queeristi orientoitunut lukija voi toisaalta kaivata ja aktiivisesti etsiä lukemisesta kohtia, jotka yllättävät ja eksyttävät, joissa valmis tieto ei enää toimikaan. Ehkä kirjoissa monet mahdottomuudet tulevat mahdollisiksi?

\section{Luettu kirjallisuus}

Aro, Tuuve. 2020. Kalasatama. Helsinki: WSOY.

Hallikainen, Niko. 2020. Kanjoni. Helsinki: Otava.

Holma, Antti. 2020. Kaikki elämästä(ni). Helsinki: Otava.

Kummu, Essi. 2020. Loiste. Helsinki: Tammi.

Lehtola, Laura. 2020. Minä valitsin sinut. Helsinki: Otava.

Paavilainen, Gekko. 2020. Yksisarvinen. Helsinki: Ntamo

Saarakkala, Janne. 2020. Sen pituinen se. Helsinki: Like.

Tuppurainen, Tiina. 2020. Kuvittelen sinut vierelleni. Hämeenlinna: Karisto.

\section{Lähteet}

Ahmed, Sara. 2006. Queer Phenomenology. Orientations, Objects, Others. Durham ja Lontoo: Duke UP.

Johnson, Barbara. 2014 [2002]. "Bringing Out D. A. Miller". Teoksessa The Barbara Johnson Reader, toimittaneet Melissa Feuerstein \& al, 147-154. Durham ja Lontoo: Duke UP.

Lahti, Annukka. 2021. "Sateenkaaren alla on myös ongelmia, vallankäyttöä ja eroja". Perhe ja yhteiskunta, 29.6.2021. https://www.perheyhteiskunta. fi/2021/06/29/sateenkaaren-alla-on-myos-ongelmia-vallankayttoa-jaeroja/ (luettu 12.8.2021).

Luhtaniemi, Milka. 2021. "Tulivuoren unta - Niko Hallikaisen Kanjoni”. Noesis, 28.4.2021. https://noesis.fi/tulivuoren-unta-niko-hallikaisen-kanjoni/ (luettu 12.8.2021)

Miller, Meredith. 2018. "Lesbian, Gay and Trans Bildungsromane". Teoksessa A History of the Bildungsroman, toimittanut Sarah Graham, 239-266. Cambridge UP.
SQS

1-2/2021 